\title{
Maternal and Perinatal Outcome of Multiple Pregnancy in a Tertiary Care Hospital of Bangladesh
}

\author{
Most. Sabina Yeasmin ${ }^{1^{*}}$ \\ Md Jalal Uddin ${ }^{2}$ \\ Shireen Akter Khanam ${ }^{3}$ \\ 1 Department of Obstetrics \& Gynaecology \\ Chattogram Maa-0-Shishu-Hospital Medical College \\ Chattogram, Bangladesh.
}

${ }^{2}$ Department of Community Medicine Chattogram Maa-0-Shishu-Hospital Medical College Chattogram, Bangladesh.

${ }^{3}$ Department of Obstetrics \& Gynaecology Rangamati Medical College Rangamati, Bangladesh.
*Correspondence to:

Dr. Most. Sabina Yeasmin Associate Professor

Department of Obstetrics \& Gynaecology

Chattogram Maa-0-Shishu-Hospital Medical College Chattogram, Bangladesh.

Mobile : +8801914339095

Email: drsabinah@yahoo.com

Date of Submission : 15.05 .2019

Date of Acceptance : $\quad 30.06 .2019$

www.banglajol.info/index.php/CMOSHMCJ

\begin{abstract}
Background: Multiple pregnancies are prone to be associated with adverse maternal and perinatal outcome. The incidence of multiple pregnancies has shown a significant increase over the last decades. This study aimed to determine the maternal and perinatal outcome in a tertiary teaching hospital.
\end{abstract}

Materials and methods: This prospective observational study was conducted in Chattogram-Maa-O-Shishu-Hospital Medical College, from July 2014 to June 2016. A total of 173 multiple pregnant women having 28 weeks completed gestation admitted for delivery were consecutively included in the study. Maternal and perinatal outcome were investigated.

Results: The results show that the number of multiple pregnancies delivered during study periods was 173 with the incidence of 1.7\% among total deliveries. There were 5 triplets pregnancies among these cases. The women with multiple pregnany were relatively older. There were no maternal mortality. Pregnancy complications were remarkabely higher. The main maternal adverse outcome were preterm delivery (84.97\%), anaemia (39.88\%), pregnancy induced hypertension (28.97\%), premature rupture rupture of membrane (28.32\%), postpartum haemorrhage (16.76\%), antepartum haemorrhage (11.9\%). The mean gestational age at delivery was 35.39 weeks for twins and 33.3 weeks for triplets. The commonest mode of delivery was by ceasarean section. The most common neonatal complications was low birth weight and most common cause of neonatal death was prematurity and neonatal sepsis.

Conclusion: Majority of the multiple pregnancy is high risk one. So, all multiple pregnancies need early diagnosis, adequate antenatal, intra-natal and postpartum care to improve the outcome and should have mandatory hospital delivery.

Key words: Multiple pregnancy; Maternal outcome; Perinatal outcome.

\section{INTRODUCTION}

Multiple pregnancy has a global impact on both maternal and perinatal risk in any pregnancy and impacts on society in terms of both social and economic effects ${ }^{1}$. The incidence of multiple gestations has risen significantly over several decades, primarily due to increased use of fertility drugs for ovulation induction, superovulation and Assisted Reproductive Technologies (ART) such as in vitro fertilization. In USA, the incidence of multiple gestations now 3\% of all pregnancies and twins comprise $25-30 \%$ of deliveries resulting from assisted reproductive technologies ${ }^{2}$. Although twins occur in approximately one of 80 pregnancies, corresponding to $2.6 \%$ of all newborns, they account for $12.2 \%$ of preterm births and $15.4 \%$ of neonatal deaths ${ }^{3,4}$. Recent data indicate that, overall $52.2 \%$ of multiple births deliver before 37 weeks and $10.7 \%$ prior to 32 weeks $^{5}$. This is the major cause 
of neonatal death in multiple pregnancies, mortality rates are up to seven times higher in twins than singleton pregnancies, in triplets and higher-order pregnancies, rates of nearly 40 per 1000 live births have been recorted ${ }^{6}$. In addition, these pregnancies are prone to complications inherent to twinning, such as acardiac fetus, conjoined twins and twin-twin transfution syndrome. In addition the risk of congenital anomalies is about 1.7 times higher than among singleton pregnancies and more significant in monozygotic pregnancies ${ }^{7,8}$.

Preterm birth is observed in approximately 54\% of all twin pregnancies, half of these births have an iatrogenic origin and are related to maternal or fetal complications while the other half consist of cases of spontaneous premature labour or premature membrane rupture ${ }^{4}$.

All of these factors explain the high perinatal mortality observed in multiple pregnancies which is five to six times higher when compared to single on pregnancies ${ }^{9}$. When analyzed according to choronicity, monochorionic pregnancies present two to three times higher risk than dichorionic pregnancies $^{10,11}$.

The objective of this study was to describe the maternal and perinatal outcome in multiple pregnancies delivered in a tertiary care hospital.

\section{MATERIALS AND METHODS}

This prospective observational study was conducted in the Department of Obstetric and Gynaecology, Chattragram MaaO-Shishu Hospital Medical College (CMOSHMC), Chattogram, Bangladesh from July 2014 to june 2016. The total number of cases were 173 .

\section{Inclusion criteria:}

All the women with multiple pregnancy completing 28 weeks of gestation with or without meidcal and obstetrical complications and had delivered in our hospital, were included in this study.

\section{Exclusion criteria:}

Those multiple pregnancies who were admitted for observation and discharged and did not come for follow up.

The patients fulfilling the eligibility criteria were followed from admission to discharge, detailed analysis of the medical report of these cases, both mother and neonates. The data included demographic details, present and past history, family history, antepartum, intrapartum, postpartum complications, neonatal outcomes and complications and perinatal mortality. Multifetus delivered in the hospital, if admitted in the neonatal unit were also followed up to their discharge or for 7 days which was shorter. Patients requiring transfer to other Department of the hospital were also followed in the same way. Necessary information was collected in a pre-designed data sheet and finally the finding were compiled and analysed.

\section{RESULTS}

During the study period, the total number of deliveries were 9,894 . The number of multiple pregnancies delivered during the same period were 173. Among them twins and triplets were 168 and 5 respectively. The overall incidence of multiple pregnancies were $1.7 \%$ of deliveries.

Majority of the women 125 (72.5\%) were in 20-30 years old and mean maternal age at presentation was 24.19 years. Most of them were multipara $151(87.2 \%)$ and unbooked cases 153 $(88.43 \%)$. More than three-fourth of the patients 147 (84.97\%) had preterm delivery (Table I). Maximum patients 125 (74.40\%) had no known aetiological factors. Only $22(13.09 \%)$ patients had family history of twin pregnancy, history of ovulation inducing drugs was present in $21(12.13 \%)$ cases. Five $(2.89 \%)$ patients conceived after stoppage of oral contraceptive pills (Table II). Spontaneous preterm labour was the common maternal complication 89 (51.44\%) followed by anaemia 69 (39.88\%), premature rupture of membrane 49 (28.32\%) hypertension 50 (28.97\%), PPH 29 (16.76\%), APH 20 (11.9\%) UTI 14 (8.09\%), GDM 10 (6\%), chorioamnionitis 3 (1.3\%). Puerperal pyrexia due to UTI and wound infection were in 2 cases and vulval haematoma was in 1 cases (Table III).

Thirty two (19.1\%) patients of twin pregnancy had vaginal delivery and $136(80.9 \%)$ were delivered by caesarean section (Table IV). In one patient first twin was delivered by vaginal route at home and $2^{\text {nd }}$ twin delivered by LSCS as membrane was ruptured, all liquor drainout and presentation was transverse. Higher caesarean section rate due to non-vertex presentation of first twin 59(34.1\%) and $2^{\text {nd }}$ twin $26(15.02 \%)$, premature rupture of membrane with oligohydramnios 22 (16.17\%) foetal distress 5 (3.67\%) single fetal demise $3(2.2 \%)$ previous caesarean section $18(10.04 \%)$ non progress of labour $4(2.94 \%)$. In case of triplets cesarean section were $4(80 \%)$ and vaginal delivery was $1(20 \%)$.

Table I : Demographic and obstetric characteristics of the patients

$\begin{array}{lrc}\begin{array}{l}\text { Demographic \& } \\ \text { obstetric features }\end{array} & \text { Twin Number (\%) } & \text { Triplets Number (\%) } \\ \text { Age } & & \\ <20 & 31(18.45 \%) & - \\ 20-30 & 121(72 \%) & 4(80 \%) \\ 30-40 & 16(9.52 \%) & 1(20 \%) \\ \text { Parity } & & \\ \text { Parity : } 0 & 20(11.9 \%) & 2(40 \%) \\ \text { Parity: } 1-2 & 140(83.33 \%) & 3(60 \%) \\ \text { Parity : } \geq 3 & 8(4.76 \%) & - \\ \text { Period of } & & \\ \text { Gestation (weeks) } & 15(8.92 \%) & 1(20 \%) \\ 28-32 \text { weeks } & 127(75.59 \%) & 4(80 \%) \\ 33-36 \text { weeks } & 26(15.47 \%) & - \\ \geq 37 & \text { Mean } & \text { Mean } \\ & \text { gestations: } 35.39 \text { weeks } & \text { gestation: } 33.5 \text { weeks } \\ & 19(11.30) & 1(20 \%) \\ \text { Antenatal Visits } & & 4(80 \%) \\ \text { Booked (3 visits) } & 149(88.69 \%) & \\ \text { Unbooked } & & \\ (<3 \text { visits) } & & \end{array}$


Table II : Distribution of patients by probable aetiological factors

\begin{tabular}{lrc} 
Parameters & Twin Number ( \%) & Triplet Number (\%) \\
$\begin{array}{l}\text { Family history of } \\
\text { multiple pregnancy }\end{array}$ & $22(13.09 \%)$ & - \\
$\begin{array}{l}\text { Pregnancy after taking } \\
\text { ovulation inducing drugs : }\end{array}$ & $17(10.11 \%)$ & $4(80 \%)$ \\
$\begin{array}{l}\text { Pregnancy within } 3 \text { months of } \\
\text { stoppage OCP }\end{array}$ & $4(2.38 \%)$ & $1(20 \%)$ \\
None & $125(74.4 \%)$ & - \\
\hline
\end{tabular}

Table III : Complications encountered by the mothers

$\begin{array}{lll}\text { Complications } & \text { Twin number (\%) } & \text { Triplet number (\%) } \\ \text { Anaemia } & 64(38 \%) & 5(100 \%) \\ \text { Hyperemesis gravidarum } & 10(5.9 \%) & 5(100) \\ \text { Hypertention (PIH \& preeclamsia) } & 47(27.97 \%) & 3(60 \%) \\ \text { Polyhydramnios } & 17(10.1 \%) & 1(20 \%) \\ \text { Postpartum haemorrhage (PPH) } & 27(16 \%) & 2(40 \%) \\ \text { Antepartum haemorrhage (APH) } & 20(11.9 \%) & - \\ \text { Pre term labour } & 85(50.6 \%) & 4(80 \%) \\ \text { PROM } & 47(28 \%) & 2(40) \\ \text { Pre-term elective LSCS } & 14(8.33 \%) & 4(80 \%) \\ \text { Gestational diabetes } & 10(6 \%) & \\ \text { UTI } & 13(8 \%) & 1(20 \%) \\ \text { Chorioamnionitis } & 3(1.3 \%) & - \\ \text { Complications of operative delivery: } & 3(1.7 \%) & - \\ \text { No complications } & 27(16 \%) & -\end{array}$

Table IV : Distribution of patients by their mode of delivery

\begin{tabular}{lcc} 
Mode of delivery & Twin number (\%) & Triplet number (\%) \\
Vaginal delivery & $32(19.1 \%)$ & $1(20 \%)$ \\
LSCS & $136(80.9 \%)$ & $4(80 \%)$ \\
\hline
\end{tabular}

Table V : Distribution of patient by fetal presentation

\begin{tabular}{lr} 
Presentation & Number (\%) \\
Twin & \\
Vertex-Vertex & $81(48.21 \%)$ \\
Vertex-breech & $24(14.28)$ \\
Vertex-transverse & $4(2.38 \%)$ \\
Breech-vertex & $30(17.85 \%)$ \\
Breech-Breech & $19(11.30)$ \\
Breech-transverse & $8(4.76 \%)$ \\
Transverse-vertex & $1(0.59 \%)$ \\
Transverse-transverse & $1(0.59 \%)$ \\
Triplet & \\
Vertex-Breech-vertex & $2(40 \%)$ \\
Vertex-vertex-vertex & $1(20 \%)$ \\
Vertex-Breech-Breech & $2(40 \%)$ \\
\hline
\end{tabular}

Table VI : Distribution of patient by chorionicity of the placenta

$\begin{array}{lrc}\text { Chorionicity } & \text { Twin Number (\%) } & \text { Triplets Number (\%) } \\ \text { Monochorionic } & 55(32.73 \%) & - \\ \text { Dichorionic } & 113(67.26 \%) & - \\ \text { Trichorionic } & - & 5(80 \%)\end{array}$

Table VII : Distribution of multiple pregnancies by Birth weight of baby

\begin{tabular}{llllll} 
Birth weight (gm) & Twin $(\mathrm{n}=330)$ & \multicolumn{4}{c}{ Triplet (n=15) } \\
& $1^{\text {st }}(\mathrm{n}=168)$ & $2^{\text {nd }}(\mathrm{n}=168)$ & Ist $(\mathrm{n}=5)^{\text {nd }}(\mathrm{n}=5)$ & $3^{\text {rd }}(\mathrm{n}=5)$ \\
$<1000$ & $5(2.97 \%)$ & $12(7.14 \%)$ & - & $1(20 \%)$ & $2(40 \%)$ \\
$1000-1500$ & $19(11.30 \%)$ & $72(42.85 \%)$ & $1(20 \%)$ & $2(40 \%)$ & $3(60 \%)$ \\
$1500-2500$ & $124(73.80 \%)$ & $78(46.42 \%)$ & $3(60 \%)$ & $2(40 \%)$ & - \\
$2500-2800$ & $20(11.90 \%)$ & $6(3.5 \%)$ & $1(20 \%)$ & - & -
\end{tabular}

Table VIII : Distribution of multiple pregnancies by perinatal complications

\begin{tabular}{llllll} 
Complications & \multicolumn{2}{l}{ Twins (n=336) } & \multicolumn{2}{l}{ Triplets (n=15) } \\
& $1^{\text {st }(\mathrm{n}=168)}$ & $2^{\text {nd }}(168)$ & Ist(n=5) & $2^{\text {nd }(\mathrm{n}=5)}$ & $3 \mathrm{rd}(\mathrm{n}=5)$ \\
\hline Macerated stillbirth & $11(13.6 \%)$ & $12(7.1 \%)$ & - & - & $1(20 \%)$ \\
Fresh stillbirth & & $2(1.19 \%)$ & $4(2.97 \%)$ & - & - \\
Early neonatal death & $2(1.19 \%)$ & $5(3.57 \%)$ & - & - & $2(40 \%)$ \\
Admission in intensive & & & & & \\
care unit & $30(17.85 \%)$ & $64(38.09 \%)$ & $1(20 \%)$ & $2(40 \%)$ & $4(80 \%)$ \\
IUGR & $10(5.95 \%)$ & $17(10 \%)$ & - & $2(40 \%)$ & $5(100 \%)$ \\
Birth asphyxia & $18(10.7 \%)$ & $39(23.21 \%)$ & $1(20 \%)$ & $3(60 \%)$ \\
Septicaemia & $7(4.16 \%)$ & $10(5.95 \%)$ & $1(20 \%)$ & $1(20 \%)$ & $2(40 \%)$ \\
Congenital anomaly & $4(2.38 \%)$ & $2(1.19 \%)$ & - & - & -
\end{tabular}

The commonest intrapartum fetal presentation was vertex-vertex $81(48.21 \%)$ cases followed by breech-vertex 30 (17.28\%), vertex-breech 24 (14.28\%), breech-breech 19 (11.30\%), breechtransverse 8 (4.76\%), vertex-transverse 4 (2.38\%) and transverse-transverse respectively in twins. There were 113 (67.26\%) dichorionic twins and 55 (32.7\%) monochorionic twins (Table V).

In case of triplets intrapartum fetal presentation vertex-Breechvertex 2 (40\%), Vertex-Breech-Breech 2 (40\%) and vertex-vertexvertex 1 (20\%). All the triplets were trichorionic (Table VI).

The average interval between delivery of the first and second twin was 14.3 minutes and longest being 196 minutes. The average interval between delivery of the first and second triplets was 2.6 minutes, the longest being 10 minutes, the interval between delivery of the $2^{\text {nd }}$ and $3^{\text {rd }}$ triplet was average 2.5 minutes and longest 5 minutes.

Maximum twin's birth weight was between 1500-2500 gm. 5 triplets birth weight was $<1000$ gm \& 5 triplets birth weight 
There were 23 macerated stillbirth, 11 being leading fetus and 12 second twin. Total 6 were fresh still birth among them 2 leading twin and 4 second twin. There were total early neonatal death 7 , leading twin 2 and second twin 5. Total number of twins admitted in intensive care unit 94 , first twin 30 and $2^{\text {nd }}$ twin 64. Total number of congenital anomaly among twin 6 .

Among triplet macerated stillbirth 1 and early neonatal death only 2 and admission in intensive care unit 8 (Table VIII).

Causes of perinatal morbidity, very LBW due to prematurity 108 twins \& 9 Triplet, IUGR 27 Twins \& 7 Triplets, Birth asphyxia 57 Twins \& 4 Triplets, septicaemia 17 twins \& 4 Triplets.

\section{DISCUSSION}

Multifetal pregnancy is associated with poor maternal and perinatal outcomes. The higher incidence of multiple deliveries observed in our study is related to the fact that we are a tertiary care hospital focusing on care of high-risk patient. In our study incidence of multiple deliveries was $1.7 \%$ of total deliveries. The incidence of multiple deliveries was 1.9 per 1000 live birth in the study of Mahendra et al. ${ }^{12}$. The rising incidence of multiple gestations worldwide has been attributed to the increasing use of ovulation inducing agents and invitro fertilization technique ${ }^{12}$.

The mean maternal age at presentation both twin and triplets was 24.19 years and mean maternal age reported in study of Mahendro et al. was 26 years both twin and triplets ${ }^{12}$.

The present study showed that about $87.28 \%$ of the women both twin and triplets were multigravida which was almost similar to the study report of Spellacy et al. where frequency of twining multigravida was $84.2 \%{ }^{13}$.

The average gestation at which twin deliveries occurs was 35.5 weeks and triplets was 33.5 weeks in our study and in the study of Mahendro et al. showed the average gestation of twin 35 weeks and for triplets it was 33 weeks ${ }^{12}$.

About $74.4 \%$ of cases resulted from spontaneous conception. This findings is in contrast to other studies where the frequency of assisted reproduction techniques conceived pregnancies reaches $50 \%{ }^{14}$. But higher incidence of spontaneous conception in the study Renata et al. was $95 \%{ }^{15}$. this difference is explained by the profile of patients at our and Assunco A.R. hospital who are from as social stratum that has no access to treatment.

In the present study, $13.09 \%$ of mother showed family history of twin pregnancy compaired to $19 \%$ and $30 \%$ in studies by Chowdhury and Sultana respectively ${ }^{16,17}$. Twin after ovulation inducing drugs was $10.11 \%$ in our study compaired to $17 \%$ and $14 \%$ in the studies by Chowdhury and Sultana respectively ${ }^{17,18}$. These two studies showed no other known aetiological factors but in our study we found $4(2.38 \%)$ and 1 (20\%) triplets to conceive within three months of stoppage of OCP.
The incidence of preterm and term delivery in our study $84.97 \%$ and $15.03 \%$ respectively and no pregnancy crossed the Expected Date of Delivery (EDD). However, Paiernik et al. Chowdhury and Sultana showed lower rates of pre-term delivery in their studies $(50.7 \%, 41.5 \% \text { and } 44 \% \text { respectively })^{18,16,17}$. The reason of higher rates of preterm delivery in the present study might be that all the patients were complicated multiple pregnancy which compelled us to terminate the pregnancy earlier.

There was no maternal mortality in this study consistent with the study Mahendra et al. Chowdhury and Sultana also did not report any maternal mortality ${ }^{12,16,17}$. However, one study done in Nigeria described a maternal mortality rate of $2 \%$ for Twin pregnancy ${ }^{19}$. But maternal morbidities were significantly high in all these studies.

In the present study, spontaneous preterm labour (51.44\%) was the common maternal complication which consistent with the study by Chowdhury $16(43.4 \%)$ and Hashimoto et al. 20 $(59 \%)^{16,20}$. Anaemia present in our study $(39.88 \%)$ Chowdhury found anaemia in $35.8 \%$ cases, but Spellacy et al showed anaemia in $9.4 \%$ cases $^{16,13}$. As the study by Spellacy et al was done in a developed country, so it is quite usual that their population would have a much higher haemoglobin level than than that our population ${ }^{13}$.

In this study premature rupture of membrane were $28.32 \%$ cases which consistent with the study of Sultana et al. where $28 \%$ cases was PROM $^{21}$. However, Chowdhury, Sultana and Mahendra et al. showed PROM occurred in 3.8\%, 10\% and $8.6 \%$ patient respectively which were unusual low for multiple pregnancy $^{16,17,12}$.

Hypertension (Including PIH and pre-eclamsia) was also observed to be higher $(28.90 \%)$ in the present study compaired to that of Sultana et al. (28\%) and Spellacy et al. (12.9\%) and postpartum haemorrhage occur (17.34\%) cases which bears consistency with the findings of Sultana et al. (16\%) and Chowdhury $(18.9 \%)^{21,13,20,16}$.

Most of the babies were delivered preterm ( $80.9 \%$ by ceasarean section and $19.1 \%$ vaginal delivery). But in the study of Sultana et al. vaginal delivery $30 \%$ and cesarean section $70 \%$. Higher rate of cesarean section was due to non-vertex presentation of first twin $(34.1 \%)^{21}$.

This study showed $48.21 \%$ was vertex-vertex presentation, $16.7 \%$ was vetex-nonvertex, $18.5 \%$ nonvertex (first twin) and both non-vertex $16.7 \%$. Sultana et al. and Chowdhury in their studies found majority of fetal presentation was vertex-vertex $48 \%$ \& $47.5 \%$ followed by vertex-nonvertex $16 \%$ \& $26 \%$ respectively and first twin non-vertex $36 \%$ and $26.1 \%$ respectively ${ }^{21,16}$.

There were $67.26 \%$ dichorionic and 32.73\% monochorionic twins which consistent with the study Mahendro et al. where $67 \%$ dichorionic twins and $33 \%$ monochorionic twins ${ }^{12}$.

In case of triplets all cases were trichorionic and triamniotic which were similar to that of the study of Mhendra et al. ${ }^{12}$. 
Low birth weight was the most common indication for neonatal admission on as shown other studies ${ }^{12,21}$. We observed perinatal mortality 39 (111 per 1000 birth) which was almost near to the study of Sultana et al. Chowdhury and Sultana ${ }^{21,16,17}$.

\section{CONCLUSION}

Majority of the multiple pregnancy is high risk one. So, all multiple pregnancies need early diagnosis, adequate antenatal, intra-natal and post-partum care to improve the outcome and should have mandatory hospital delivery.

DISCLOSURE

All the authors declared no competing interest.

\section{REFERENCES}

1. Kilby D.M and Oepkes D. Multiple pregnancy. Edmonds D.K. Dewhurst's Text book of Obstetrics \& Gynaecology. $8^{\text {th }}$. WileyBlackwell.London. 2012;250.

2. Bush C.M \&pernollL.Mmultiple Gestation. Decherney H.A, Nathan L, Laufer N, Roman S.A. Current Diagnosis \& treatment of obstetrics \&gynaecology. $11^{\text {th }}$. McGraw Hill.New Yourk. 2013;301.

3. Ghai V, Vidyasagar D. Morbidity and mortality factors in twins. An epidemiologic approach. Clin Perinatol, 1988;15(1):123-140

4. Gardner Mo, Goldenberg RL, Cliver SP, Tucker JM, Nelson KG, Copper RL. The origin and outcome of pretermtwin pregnancies.Obstet Gynecol.1995;85(4):553-557.

5. Information Services Division, NHS Scotland. Scottissh Perinatal and infant mortality and morbidity Report 2008. Available at:www.isdscotland.org/Health-Topic/Maternity-and-Births/publications/index.asp\#742.

6. Confidential Enquiry into Maternal and child health.Perinatal Mortality 2007. London:CEMACH, 2009. Available at www.cemach.org.uk/getattachment/bc6ad9f0-5274-486d-b61a-8770a0ab43e7/Perinatal mortality-2007 aspx.

7. Glinianaia SV, Rankin J, Renwick M.Time trends in twin perinatal mortality in northern England. 1982-94.Northern Region Perinatal mortality servey Steering Group. Twin Res 1998;1(4):89-95.

8. Brizot M,Fujita M, Reis N, Banduki J, Schultz R,Miyadahira S et al.Malformcoesfetataisemgestacomultipla.Rev Bras GynecolObtet. 2000;22 (8): 511-517.

9. Russel RB, Petrini JR, Damus K, Mattgson DR, Schwarz RH. The changing epidemiology of multiple births in the United States.Obtetgynecol 2003; 101 (1): 129-135.

10. Hack KE, Derks JB, Elias SG, Franx A, Roos EJ, Voerman SK et al. Increased perinatal mortality and morbidity in monochorionic versus dichorionic twin pregnancies: Clinical implications of a large Dutch cohort study.Obstet Gynecol. 2008; 115(1):58-67.

11. Loos R, Derom C, Vlietnck R, Derom R. The East Flanders Prospective Twin Survey (Belgium): A population-based register. Twin Res. 1998;1(4):167-175.

12. R.P. Mahendra, J.K. Bikash, D.Deepak. Maternal and perinatal outcome in multiple pregnancy.A study at teaching Hospital, department of obstetrics \& gynaecology, MTH, Pokara, Nepal. American Journal of Public Health Research. 2015;5a(3):135-138.

13. Spellacy WN, Handler A.Ferre CD. A case comtrol study of 1253 twin pregnancies from 1982-1987.Perinatal Data Base. 1990;75:198-199.

14. Derom C, DromR.The east flanders prospective twin survey .In Blickstein I, Keith LG, editors.Multiple pregnancy: Epidemiology, gestation and perinatal outcome. $2^{\text {nd }}$ ed .Andover: Thompson publishing Services. 2005;39-46.

15. Renata AA, L. w. Adolfo, B.L. Maria, KJL. Vera, Z. Marcelo.Perinatal outcome of twin pregnancies delivered in a teaching Hospital. Study conducted at the clinica obstetrics do Hospital das Clinicas da Medicina da Universida de Sao Paulo,SaoPaulo,SP.RevAssoc Med Bras. 2010; 56(4): 447-451.

16. Chowdhury S. Clinical study on twin pregnancy.FCPS, Bangladesh College physicians and Surgeons, Dhaka. 1998.

17. Sultana H. Feotal and maternal outcome of twin pregnancy - A study of 50 cases, Bangladesh college of physicians and Surgeons, Dhaka. 2002.

18. Papiernik. E, Keith L, Oleszczuk JJ, Cervantes A. What interventions are useful interventions in reducing the rate of preterm delivery in twins. 2004

19. Senat MV, Ancel PY, Colle AHB, Breart G. How does multiple pregnancy affect maternal mortality and morbidity? In clinical obstet \& Gynaecol 1998; 79-83.

20. Hashimoto B, Callen PW, Filly RA, Laros RK. Ultrasound evaluation of polyhydramnios in twin pregnancy. AM J Obstet \& Gynaecol. 1986;154:1069.

21. Sultana M, KhatunS, Ara R, Saha K A, Akhter P, Shah ABS. Maternal and perinatal outcome of twin pregnancy in a Tertiary Hospital.The study was conducted in BSSMU Hospital Bangladesh.Ibrahim Card Med J.2011:1(2):35-39. 